\title{
The Influence of Information Sharing in the Supply Chain Process on Business Performance: An Empirical Study
}

\author{
Bayram TOPAL ${ }^{1}$, Hasan SAHIN ${ }^{2 *}$ \\ ${ }^{1}$ Sakarya University, Sakarya University Esentepe Campus, 54187, Serdivan / Sakarya, Turkey \\ btopal@sakarya.edu.tr \\ ${ }^{2}$ Dumlupinar University, Simav Vocational School Dr. Naci Eren Campus, 43500, Simav/ Kutahya, Turkey \\ hasan.sahin@dpu.edu.tr (*Corresponding author)
}

\begin{abstract}
Supply chain management has become one of the focal points of competition nowadays. The importance of information sharing in supply chain management is also increasing in terms of business performance improvement. In this study, five different models were developed to investigate the effect of information sharing in the supply chain process of businesses on cost, flexibility, response, delivery and financial performance. The relationships among these models are examined by means of a structural equation model (SEM). This paper is focused on supply chain process, supply chain flexibility, environmental uncertainties and information sharing latent structures whose cumulative effects on the determined performance indicators have been examined. The survey data obtained from the companies within the scope of the ISO (Istanbul Chamber of Industry) 1000 were used in the analyses conducted, whose results proved that all the suggested models were adequate in terms of validity and reliability. Furthermore, it was determined in all models that environmental uncertainties affect the supply chain process, while supply chain flexibility affects the supply chain process and information sharing.
\end{abstract}

Keywords: Business Performance, Supply chain, Structural Equation Model.

\section{Introduction}

To survive and compete in today's economy, the manufacturing sector urgently needs production, procurement, production technologies, capital, labor, productivity, sharing, extending to today's standards, and appropriate knowledge and information technologies. There is a great number of studies in the scientific literature that focus on information sharing in the supply chain and on measuring the supply chain performance. The majority of these studies either address information sharing in the supply chain or supply chain performance. In the study conducted, Demirel [3] emphasized the influence of information and information sharing on business performance in the banking sector. By referring to different samples from the industry, Lee and Whang [16] investigated how and why different types of information, such as inventory, sales, demand forecasting, order status, and production planning, are shared. Torkul et al. [33] aimed to improve efficiency, rapid responsiveness and agility in the supply chain by taking an innovative approach to information sharing through an integrated supply chain design. Erjiang et al. [5] investigated how to increase online collaboration in competitive supply chains and cost-sharing decisions. In their study, Hung et al. [9] stated that an information sharing strategy contains the sharing and coordination of information and they had a strong impact on reducing the uncertainty of supply chain and increasing the supply chain performance. Baihaqi and Sohal [1] tested the relationship between the level of information sharing and organizational performance.

This study aims to investigate the influence of information sharing process on business performance in supply chain management. For this purpose, conceptual models were developed by employing a structural equation model (SEM). In the study, variables affecting business performance during information sharing in the supply chain were preliminarily determined. Therefore, five different models were developed to evaluate business performance. By using these models, the influence of information sharing on business performance (cost, flexibility, response, delivery, and financial performance) was analyzed, and, thus, the study focused on information sharing in the supply chain. The second section presents the theoretical background of information sharing in the supply chain and the relevant scientific literature. The method used in the current study was presented in the third section, and the fourth section includes the analysis of the study results. The results and discussion drawn from the analysis are thoroughly examined in the fifth section. 


\section{Theoretical Background and Literature Review}

\subsection{Supply Chain Process (SCP)}

The concept of supply chain management (SCM) was introduced in the early 1980s [14]. Understanding and implementing the supply chain have become an essential prerequisite for staying in the global competition and increasing profits [18]. SCM as a concept has been widely accredited to a Booz Allen consultant named Keith Oliver who defined the concept in 1982 as follows: "SCM is the process of planning, implementing, and controlling the operations of the supply chain with the purpose to satisfy customer requirements as efficiently as possible. SCM spans all movement and storage of raw materials, work-in-process inventory, and finished goods from point-of-origin to point-of-consumption". According to Fiala [6], material flow, financial flow, and information flow in the supply chain system connect the concerned parties in both directions. For effective supply chain management, the Supply Chain Operation References (SCOR) model was proposed by the Supply Chain Council. The SCOR model approaches all supply chain structures with a sector-independent point of view and defines these structures under five fundamental processes as "planning", "supply", "production", "distribution", and "return". The studies in the relevant scientific literature reported that the five supply chain processes in the SCOR model had a positive effect on business performance [13]. Furthermore, there are studies on the subject carried out by Yigitbasioglu [41], Marinagi et al. [20], and Sagbas [26].

\subsection{Supply Chain Flexibility (SCF)}

Flexibility is defined as the rapid adaptability of firms to changes with lower costs and minimum losses in performance [34]. Topoyan [32] defined supply chain flexibility as the adaptability of the supply chain to changing market conditions and the demands and expectations of customers. Vickery et al. [35] revealed the dimensions of which supply chain flexibility consists and their relationship with environmental uncertainty, business performance, and functional interface. Topoyan [32] mentioned the absence of studies on the effect of different flexibility types on each other and on business performance. Moreover, there are studies on the subject conducted by Liao [19], Qrunfleh and Tarafdar [24], Huo et al. [11], and Jin et al. [12].

\subsection{Information Sharing (IS)}

Information sharing has become an important research subject in supply chain management. The understanding of strategic and appropriate information sharing remained limited, albeit the effort to investigate the subject [9 and 10]. Information sharing is critical in the coordination of supply chain activities [6]. Yigitbasioglu [41] defines interfirm information sharing as the sufficiently elaborate, frequent, and timely information shared between buyers and key suppliers to meet the needs of a firm. Information sharing is an important cooperation component in supply chain management [17]. Zhou and Benton [44] integrated supply chain practices with information sharing in supply chain management. A review of the studies in the scientific literature showed that timely access to the customer demand information lowers inventory costs and allows the effective use of resources.

\subsection{Environmental Uncertainty (EU)}

Uncertainty is one of the most common and determinant properties of all complex systems. Customer requests, competition conditions, and technological developments create an increasingly ambiguous environment. Hence, as the uncertainty of the environment of businesses increases, the need for supply chain management grows [32]. There are two types of uncertainties that may emerge in the supply chain [15]: demand uncertainty is due to the inconsistency or insufficiency in demand forecasting. The difference between the actual demand level and estimated demand level has a negative effect on all decisions required in the supply chain. Supply uncertainty is the second type of uncertainty and involves the disruptions encountered while obtaining the components from the supplier. In the supply chain, the uncertainty in supply results in keeping higher amounts of stocks to promptly meet customer demands, which leads to failure in establishing an effective supply chain [32]. This situation is referred to as the whiplash effect. Businesses usually seek ways to increase information sharing to eliminate both supply uncertainty and demand uncertainty. 
Other measures to remedy supply uncertainty are to include the supplier in the process during the first stages of product design and to form supply centers [22 and 38]. Environmental uncertainty plays a vital role in the implementation of strategic supply chain initiatives.

\subsection{Business Performance (BP)}

With rapid developments in globalization and technology, businesses now compete in product and service quality, cost, speed, logistics, customer services, and after-sales services. Businesses need to keep up with this competitive environment to survive. Therefore, various studies were carried out to improve the performance of the system. Sahin and Robinson [27] investigated the effects of manufacturers' information sharing and coordination in the physical flow on system performance. Martin [21] concluded that supply chain practices had a positive effect on the raw material level and shorter cycle time, but did not have a direct effect on the financial performance of a firm. Zhou [43] analyzed the supply chain and information sharing using analytical and empirical methods in order to obtain the optimum business performance under alternative supply chain dynamics. Using the SEM, Shin et al. [30] tested the effects of a supply management orientation on the operational performance of suppliers and the competitive priorities of buyers (cost, quality, delivery, flexibility). Hung et al. [9] emphasized the importance of information sharing in supply chain management as a research subject. Albeit frequent efforts, our understanding of strategic and optimal information sharing remains limited. To fill this gap, the content of the information sharing strategy in the supply chain and especially how uncertainty in the supply chain affects the information sharing strategy and business performance were investigated in this study. An answer to the question "What is the effect of information sharing in the supply chain on business performance?" was sought. Hence, as the measures of business performance, five fundamental models were developed for cost [ 37 and 42], flexibility [12], response [4, 36 and 40], delivery [23 and 31], and financial performance [8 and 39] with respect to the theoretical background. Moreover, the summary of the scientific literature to which we referred for establishing the theoretical framework is presented in Table 1.

Table 1. The summary of the scientific literature used in the study

\begin{tabular}{|c|c|c|c|c|c|c|c|c|c|}
\hline \multirow{2}{*}{ Author [Literature] } & \multirow{2}{*}{$\mathrm{SCP}$} & \multirow{2}{*}{$\mathrm{SCF}$} & \multirow{2}{*}{ IS } & \multirow{2}{*}{ EU } & \multicolumn{5}{|c|}{ Performance Criteria } \\
\hline & & & & & $\mathrm{C}$ & $\mathrm{Fl}$ & $\mathrm{R}$ & $\mathrm{D}$ & $\mathrm{Fi}$ \\
\hline Shin et al. [30] & & & & & $\mathrm{X}$ & $\mathrm{X}$ & & $\mathrm{X}$ & \\
\hline Martin [21] & $\mathrm{X}$ & & $\mathrm{X}$ & & & & & $\mathrm{X}$ & $\mathrm{X}$ \\
\hline Liao [19] & & $\mathrm{X}$ & & $\mathrm{X}$ & $\mathrm{X}$ & & & & \\
\hline Zhou \& Benton [44] & $\mathrm{X}$ & & $\mathrm{X}$ & & & & & $\mathrm{X}$ & \\
\hline Yigitbasioglu [41] & $\mathrm{X}$ & & $\mathrm{X}$ & $X$ & & $\mathrm{X}$ & & $\mathrm{X}$ & \\
\hline Hung et al. [9] & & $\mathrm{X}$ & $\mathrm{X}$ & $\mathrm{X}$ & $\mathrm{X}$ & & & $\mathrm{X}$ & \\
\hline Wang \& Wang [36] & & & & & $\mathrm{X}$ & & $\mathrm{X}$ & & $\mathrm{X}$ \\
\hline Prajogo \& Olhager [23] & & & $\mathrm{X}$ & & $\mathrm{X}$ & $\mathrm{X}$ & & $\mathrm{X}$ & \\
\hline Baihaqi \& Sohal [1] & & & $\mathrm{X}$ & & $\mathrm{X}$ & & & $\mathrm{X}$ & $\mathrm{X}$ \\
\hline Ye \& Wang [40] & & & $\mathrm{X}$ & & $\mathrm{X}$ & & $\mathrm{X}$ & & \\
\hline Singh \& Power [31] & & & $\mathrm{X}$ & & & & & $\mathrm{X}$ & $\mathrm{X}$ \\
\hline Youn et al. [42] & & $\mathrm{X}$ & $\mathrm{X}$ & & $\mathrm{X}$ & $X$ & $\mathrm{X}$ & & \\
\hline Wu et al. [39] & & & $X$ & & & & & $X$ & $\mathrm{X}$ \\
\hline Huo et al. [10] & & & $\mathrm{X}$ & $\mathrm{X}$ & & & $\mathrm{X}$ & $\mathrm{X}$ & \\
\hline Qrunfleh \& Tarafdar [24] & & $\mathrm{X}$ & $\mathrm{X}$ & & & & & & $\mathrm{X}$ \\
\hline Jin et al. [12] & & $\mathrm{X}$ & & & & $\mathrm{X}$ & & $\mathrm{X}$ & \\
\hline Sagbas [26] & $\mathrm{X}$ & & & $X$ & & & & & $\mathrm{X}$ \\
\hline Dwaikat [4] & & $X$ & $\mathrm{X}$ & & & & $X$ & $\mathrm{X}$ & \\
\hline
\end{tabular}

(SCP: Supply Chain Process, SCF: Supply Chain Flexibility, IS: Information Sharing, EU: Environmental Uncertainty, C: Cost, Fl: Flexibility, R: Response, D: Delivery, Fi: Financial) 


\section{Material and Method}

\subsection{Material}

A questionnaire was sent to 231 firms in the study prepared by referring to the relevant scientific literature and previous studies focusing on the same subject. It was composed by a group of experts. The scales used in the questionnaire are given in Appendix A. The questionnaire was in the form of a seven-point Likert-type scale to obtain a more sensitive evaluation, and it was conducted with the authorities from the large businesses included in ISO 1000. Although feedback was received from 231 firms, since questionnaires received from 28 firms contained missing answers and therefore, data received from those firms were excluded, only the data obtained from 203 firms were used in the analyses. The distribution of the large businesses in ISO 1000 by sectors was determined using the data obtained from the questionnaire and is presented in Table 2.

Table 2. Sector-based distribution of the firms included in the study

\begin{tabular}{|c|c|c|}
\hline Sector & Frequency & $\%$ \\
\hline Construction, Non-Metal Industry & 37 & 18.2 \\
\hline Food & 31 & 15.3 \\
\hline Textile & 29 & 14.3 \\
\hline Metal and Metal Goods Industry & 28 & 13.8 \\
\hline Wood, Packaging, Furniture & 16 & 7.9 \\
\hline Chemistry & 13 & 6.4 \\
\hline Automotive & 13 & 6.4 \\
\hline White Goods, Electronics Industry & 8 & 3.9 \\
\hline Energy & 8 & 3.9 \\
\hline Mining & 7 & 3.4 \\
\hline Other & 13 & 6.4 \\
\hline Total & 203 & 100 \\
\hline
\end{tabular}

\subsection{Study Hypotheses and Design}

As previously discussed in the literature review section, information sharing in supply chain management has become a critical part of business success. Supply chain management aims to obtain reduced costs, higher delivery reliability and higher profits. This study tested seven hypotheses basically.

Hypothesis 1 (H1): Environmental uncertainties in the supply chain affect the supply chain process.

Hypothesis 2 (H2): Environmental uncertainties in the supply chain affect information sharing.
Hypothesis 3 (H3): Supply chain flexibility affects the supply chain process.

Hypothesis 4 (H4): Supply chain flexibility affects information sharing.

Hypothesis 5 (H5): Effective information sharing leads to the acceleration of an effective supply chain process.

Hypothesis 6 (H6): Effective information sharing improves business performance.

Hypothesis 7 (H7): Supply chain process improves business performance.

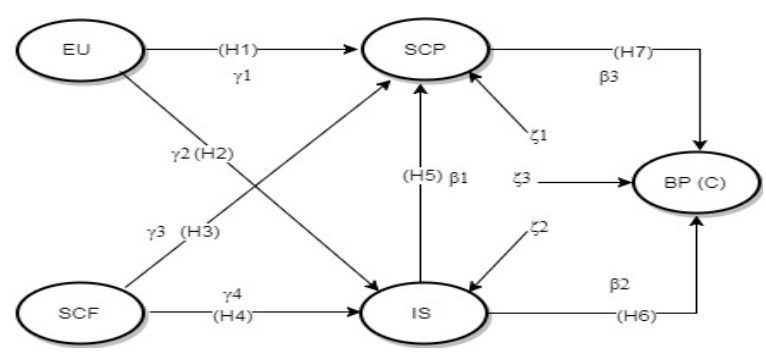

Figure 1. General covariance structure of the models (demonstrated based on the cost model)

(SCP: Supply Chain Process, SCF: Supply Chain Flexibililty, EU: Environmental Uncertainty IS: Information Sharing, BP: Business Performance, $\mathrm{C}$ : Cost)

The seven hypotheses were modeled as shown in Figure 1. The principal structures in the study are EU, SCF, SCP, IS, and BP. Each of the paths between the five latent variables determines the direction of the causality. To test the causal relationship between the structures, five covariance models related to Cost, Flexibility, Response, Delivery, and Financial performance were developed. Each of the five structural models represents the covariance structures below:

$\mathrm{y}_{1}=\gamma_{1}\left(\mathrm{x}_{1}\right)+\gamma_{2}\left(\mathrm{x}_{2}\right)+\beta_{1}\left(\mathrm{y}_{2}\right)+\zeta_{1}$

$\mathrm{y}_{2}=\gamma_{2}\left(\mathrm{x}_{1}\right)+\gamma_{4}\left(\mathrm{x}_{2}\right)+\zeta_{2}$

$\mathrm{y}_{3}=\beta_{3}\left(\mathrm{y}_{1}\right)+\beta_{2}\left(\mathrm{y}_{2}\right)+\zeta_{3}$

Here, $x_{i}$ are exogenous variables, while $y_{i}$ are endogenous variables; $x_{1}, x_{2}, y_{1}, y_{2}$ and $y_{3}$ represent EU, SCF, SCP, IS, and BP, respectively. Furthermore, $\gamma_{i}$ (gamma) and $\beta_{i}$ (beta) represent the direct causal effects of exogenous and endogenous variables, respectively; and $\zeta_{i}$ (zeta) are random disturbances. 


\subsection{Method}

Structural equation models (SEM) are statistical methods frequently used in the modeling of causal relationships between variables. They are used especially in health sciences (medicine, nursing, and psychiatry), economics, social and behavioral sciences (sociology, psychology, education, management, marketing, etc.) and sports sciences to evaluate the relationships between variables and analyze causality in the testing of theoretical models [7]. Structural equation models are statistical models that offer a confirmatory (hypothesis tests) approach to the analysis of the structural theory associated with certain phenomena. This theory usually represents "causal processes" that are composed of multivariate observations [2]. Structural equation models or relational models were developed in a chronological order starting with regression models, and followed by path models, confirmatory factor analysis models and, finally, structural equation models. The first three models mentioned above need to be understood in advance to apply structural equation models [29]. The various goodness-of-fit statistics describing the correct models that exhibit good fit to the sample data were developed. The fit statistics test the conformity of the statistics obtained from the sample data to the parameters of the proposed models. If the model fails to fit the data, the model is rejected. The expected coefficients for the mentioned fit indices are presented in Table 3 [25 and 28].
Table 3. Model fit indices

\begin{tabular}{|ccc|}
\hline $\begin{array}{c}\text { Compliance } \\
\text { Measures }\end{array}$ & Best Fit & $\begin{array}{c}\text { Acceptable } \\
\text { Compliance }\end{array}$ \\
\hline$x^{2} / d f$ & $0<x^{2} / d f<2$ & $2<x^{2} / d f<5$ \\
GFI & $0.95<\mathrm{GFI}<1.00$ & $0.90<\mathrm{GFI}<0.95$ \\
CFI & $0.97<\mathrm{CFI}<1.00$ & $0.95<\mathrm{CFI}<0.97$ \\
NFI & $0.95<\mathrm{NFI}<1.00$ & $0.90<\mathrm{NFI}<0.95$ \\
SRMR & $0<\mathrm{SRMR}<0.05$ & $0.05<\mathrm{SRMR}<0.10$ \\
RMSEA & $0<$ RMSEA $<0.05$ & $0.05<$ RMSEA $<0.08$ \\
\hline
\end{tabular}

\section{Statistical Results and Findings}

The study aims to determine the factors affecting business performance in the supply chain, reveal their relationships with each other, and investigate the effect of information sharing on business performance. Examining these factors entails using one of the multivariate dependent methods. The structural equation model is a suitable method for the simultaneous examination of multiple variables to reveal the relationships between all variables [2]. A statistically good model is composed of measurement models and structural models. A measurement model enables measuring the relationships between observed and latent variables, while a structural model reveals the relationships between dependent and independent variables. Table 4 shows the descriptive statistics for the independent and dependent variables in the study. As the statistics presented in Table 4 show, firms deemed their performance in activities related to the supply chain process (SCP) satisfactory, while they regarded their performance in activities related to supply chain flexibility and environmental uncertainty as unsatisfactory.

Table 4. Descriptive statistics for the variables

\begin{tabular}{|c|c|c|c|c|c|c|c|c|c|}
\hline \multicolumn{2}{|c|}{ Scale and Subdimensions } & $\mathrm{IN}^{*}$ & Mean & SD & \multicolumn{2}{|r|}{ Scale and Subdimensions } & $\mathrm{IN}^{*}$ & Mean & SD \\
\hline \multirow{5}{*}{ SCP } & Planning & 6 & 5.35 & 1.3 & \multirow{5}{*}{$\mathrm{SCF}$} & Product Development & 5 & 3.02 & 1.3 \\
\hline & Production & 8 & 5.14 & 1.3 & & Production Flexibility & 4 & 3.29 & 1.4 \\
\hline & Supply & 5 & 5.45 & 1.3 & & Supplier Flexibility & 4 & 2.67 & 1.3 \\
\hline & Delivery & 7 & 5.56 & 1.1 & & Delivery Flexibility & 2 & 2.4 & 1.5 \\
\hline & Return Process & 6 & 5.68 & 1.2 & & Supply Flexibility & 3 & 2.55 & 1.3 \\
\hline \multirow{4}{*}{ EU } & Supplied Uncertainty & 5 & 3.89 & 1.6 & \multirow{4}{*}{ IS } & Information Quality & 7 & 5.83 & 1.1 \\
\hline & Customer Uncertainty & 3 & 3.89 & 1.7 & & Supplier Information & 8 & 4.32 & 1.4 \\
\hline & Technology Uncertainty & 3 & 3.19 & 1.5 & & Manufacturer Information & 5 & 4.49 & 1.5 \\
\hline & Demand Uncertainty & 7 & 3.27 & 1.4 & & Information Technology Use & 13 & 5.15 & 1.2 \\
\hline \multirow{3}{*}{$\mathrm{P}$} & Cost (C) & 4 & 4.37 & 1.3 & \multirow{3}{*}{$\mathrm{P}$} & Delivery (D) & 3 & 4.81 & 1.4 \\
\hline & Flexibility (Fl) & 3 & 4.79 & 1.2 & & Financial (Fi) & 5 & 4.45 & 1.1 \\
\hline & Response (R) & 6 & 4.76 & 1.3 & & & & & \\
\hline
\end{tabular}

* IN: Item number 
Table 5. Confirmatory Factor Analysis (CFA) fit indices and reliability results

\begin{tabular}{|c|c|c|c|c|c|}
\hline $\begin{array}{c}\text { Model Compliance } \\
\text { Index }\end{array}$ & $\begin{array}{c}\text { Information } \\
\text { Sharing }\end{array}$ & $\begin{array}{c}\text { Supply Chain } \\
\text { Process }\end{array}$ & $\begin{array}{c}\text { Environmental } \\
\text { Uncertainty }\end{array}$ & $\begin{array}{c}\text { Supply Chain } \\
\text { Flexibility }\end{array}$ & $\begin{array}{c}\text { Business } \\
\text { Performance }\end{array}$ \\
\hline $\mathrm{X}^{2} / \mathrm{df}$ & $2.02^{*}$ & $2.299^{*}$ & $1.90^{* *}$ & $2.299^{*}$ & 2.872 \\
GFI & $0.901^{*}$ & $0.972^{* *}$ & $0.935^{*}$ & $0.972^{*}$ & $0.910^{*}$ \\
CFI & $0.954^{*}$ & $0.987^{* *}$ & $0.9951^{* *}$ & $0.987^{* *}$ & 0.945 \\
SRMR & $0.0512^{*}$ & $0.0266^{* *}$ & $0.0474^{* *}$ & $0.0266^{* *}$ & $0.0538^{*}$ \\
RMSEA & $0.071^{*}$ & $0.076^{*}$ & $0.065^{*}$ & $0.076^{*}$ & 0.087 \\
Cronbach Alpha $(\alpha)$ & 0.923 & 0.928 & 0.815 & 0.914 & 0.932 \\
\hline
\end{tabular}

(**) Good fit, (*) Acceptable adaptability

By adopting the information sharing in the supply chain process approach, five competitive priority models were evaluated using the cost, flexibility, response, delivery, and financial performance criteria. By including the chi-square/degree of freedom $x^{2} / d f$, Goodness of Fit Index (GFI), Comparative Fit Index (CFI), Standardized Root Mean Square Residual (SRMR), and Root Mean Square Error of Approximation (RMSEA), several general fit statistics that are preferred in structural equation modeling were used. Table 5 shows the fit indices for the five models through which the effects of information sharing in the supply chain on business performance were investigated. As can be seen from Table 5, all models were a good fit according to the $\left(x^{2} / d f\right)$ measure, while they generally exhibited adequate fit to the data according to the other measures.

\subsection{Confirmatory Factor Analysis Results}

Table 5 shows the fit indices obtained for latent variables through the confirmatory factor analysis. According to the first results obtained from the confirmatory factor analysis performed by establishing the suitable item-factor relationship for the initially planned structure of the scale, the model fit indices were generally at acceptable levels. Since no item had a factor loading below 0.40 , only the suitable covariance connections were made. The factor loadings of items and single-factor structures in each performance scale were at a sufficient level, and $t$-values for all items were significant at the level of 0.01 . The five models developed for each performance indicator are examined separately below.

\subsection{Cost Model}

As one of the subdimensions of the business performance scale, the cost performance (C) variable is the variable explained by means of the cost model. Figure 2 shows the structural equation of the cost model. As can be seen from Table 6, the analysis of the cost model showed that was 1.714 and therefore, the validity of the model was within acceptable limits. The fit index values of the model were calculated as follows: RMSEA (.059), GFI (.857), CFI (.945) and SRMR (.081). These values indicate that the model was within acceptable limits. Only the direct effect of Information Sharing (IS) on the cost performance variable was significant, while the effect of the Supply Chain Process (SCP) was not significant. Moreover, the Information Sharing (IS) variable was directly affected both by the SPF variable and the SCP variable. Furthermore, the SCP variable was affected by the Environmental Uncertainty (EU) and Supply Chain Flexibility (SCF) variables. According to the cost model, among

Table 6. Summarized results of the study models

\begin{tabular}{|c|c|c|c|c|c|}
\hline Performance Measure & Cost & Flexibility & Response & Delivery & Financial \\
\hline $\mathrm{X}^{2} / \mathrm{df}$ & $1.714^{* *}$ & $1.691^{* *}$ & $1.725^{* *}$ & $1.697^{* *}$ & $1.699^{* *}$ \\
$\mathrm{RMSEA}$ & $0.059^{*}$ & $0.058^{*}$ & $0.060^{*}$ & $0.059^{*}$ & $0.059^{*}$ \\
$\mathrm{GFI}$ & 0.857 & 0.868 & 0.887 & 0.891 & 0.876 \\
$\mathrm{CFI}$ & 0.945 & $0.951^{*}$ & $0.9518^{*}$ & 0.9488 & 0.948 \\
$\mathrm{SRMR}$ & $0.081^{*}$ & $0.078^{*}$ & $0.069^{*}$ & $0.057^{*}$ & $0.079^{*}$ \\
\hline
\end{tabular}

(*) Adequate integration (**) Good fit 
the above hypotheses, the $1^{\text {st }}, 3^{\text {rd }}, 4^{\text {th }}, 5^{\text {th }}$, and $6^{\text {th }}$ hypotheses were accepted, while the 2 nd and $7^{\text {th }}$ hypotheses were rejected.

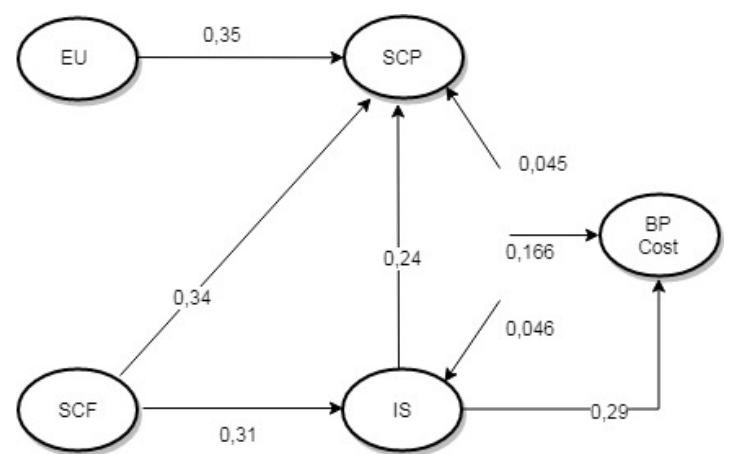

Figure 2. The structural equation of the cost model

\begin{tabular}{|c|c|}
\hline Structural Equations & $\mathrm{R}^{2}$ \\
\hline Cost $=0.88 * \mathrm{IS}$ & $\% 8$ \\
\hline $\mathrm{IS}=0.15 * \mathrm{SCP}+0.13 * \mathrm{SCF}$ & $\% 24$ \\
\hline $\mathrm{SCP}=0.23 * \mathrm{SCF}+0.21 * \mathrm{EU}$ & $\% 42$ \\
\hline
\end{tabular}

The Cost Performance (C) variable was significantly affected only by the BP variable $(b=.882$ and $p<.05)$, while only $8 \%$ of the cost performance variable was explained through the model. Since the coefficient of the BP variable was positive, increasing information sharing in the supply chain will increase the cost performance. The BP variable in the model was positively affected by the SCP $(b=.15$ and $p<.05)$ and SCF $(b=.13$ and $p<.05)$ variables. In the model, $24 \%$ of the BP variable was explained. The positive regression coefficients led to the estimation that the value of the BP variable would increase at once with the SCP and SCF variables. In the model, the SCP variable explained by $42 \%$ was positively affected by $\mathrm{SCF}(\mathrm{b}=.23$ and $\mathrm{p}<.05)$ and $\mathrm{EU}(\mathrm{b}=.21$ and $\mathrm{p}<.05)$. The positive influence coefficients suggest that the SCP variable will increase at once with the EU and SCF variables.

\subsection{Flexibility Model}

The SEM presented in Figure 3 was developed for the flexibility performance, which is one of the indicators of business performance, and the results are summarized in Table 7 . According to the model, the Flexibility Performance (Fl) variable was significantly explained only by the SCP variable. As can be seen from Table 6, according to the flexibility model analysis, $x^{2} / d f$ was 1.691 and therefore, the validity of the model was within acceptable limits.

The supply chain process (SCP) positively explained $12 \%$ of the flexibility performance
(F1). Again, according to the model, $18 \%$ of the information sharing (IS) variable was explained by supply chain flexibility (SCF), while $46 \%$ of SCP was explained by the EU, SCF, and BP variables. Based on the flexibility model, the $1 \mathrm{st}$, 3rd, 4th, 5th, and 7th hypotheses were accepted, while the 2 nd and 6th hypotheses were rejected.

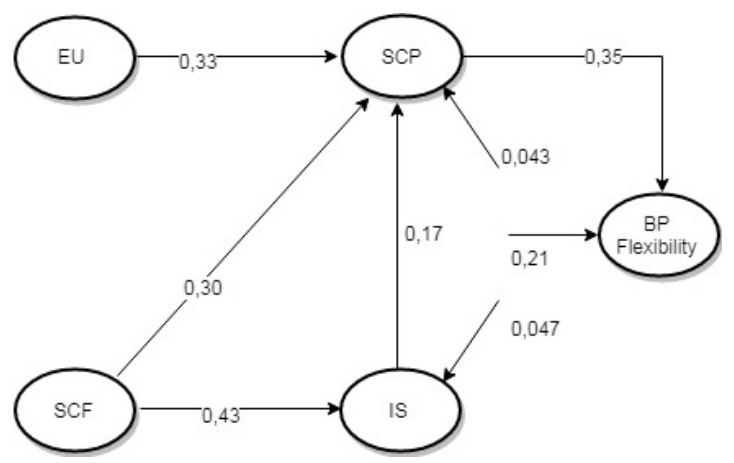

Figure 3. The structural equation of the flexibility model

\begin{tabular}{|c|c|}
\hline Structural Equations & $\mathrm{R}^{2}$ \\
\hline Flexibility $=0.650 * \mathrm{SCP}$ & $\% 12$ \\
\hline $\mathrm{IS}=0.172 * \mathrm{SCF}$ & $\% 18$ \\
\hline $\mathrm{SCP}=0.205 * \mathrm{SCF}+0.19 * \mathrm{EU}+0.27 * \mathrm{IS}$ & $\% 46$ \\
\hline
\end{tabular}

\subsection{Response Model}

The third model is the response model (R), which is one of the subdimensions of the firm performance scale, and Figure 4 shows the structure of the model, and the summarized results are presented in Table 7. As can be seen from Table 6 , the analysis of the response model showed that $x^{2} / d f$ was 1.725 and therefore, the validity of the model was within acceptable limits. Based on the response model, the $1^{\text {st }}, 3^{\text {rd }}, 4^{\text {th }}, 5^{\text {th }}$, $6^{\text {th }}$, and $7^{\text {th }}$ hypotheses were accepted, while the $2^{\text {nd }}$ hypothesis was rejected.

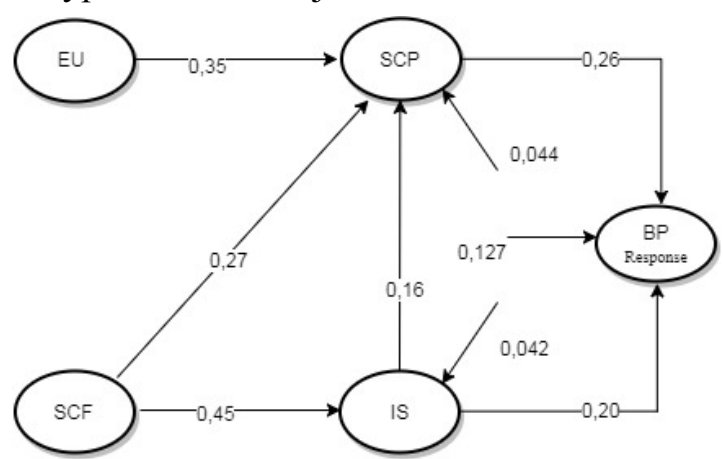

Figure 4. The structural equation of the response model

\begin{tabular}{|c|c|}
\hline Structural Equations & $\mathrm{R}^{2}$ \\
\hline Response $=0.226 * \mathrm{SCP}+0.203 * \mathrm{IS}$ & $\% 15$ \\
\hline $\mathrm{IS}=0.451 * \mathrm{SCF}$ & $\% 20$ \\
\hline $\mathrm{SCP}=0.273 * \mathrm{SCF}+0.354 * \mathrm{EU}+0.16 * \mathrm{IS}$ & $\% 45$ \\
\hline
\end{tabular}


Table 7. Regression and determination coefficients of the models

\begin{tabular}{|c|c|c|c|c|c|c|c|}
\hline Model & Affecting & Effect & Affected & $\begin{array}{c}\text { Non-standardized } \\
\text { Coefficient }\end{array}$ & $\begin{array}{c}\text { Standardized } \\
\text { Coefficient }\end{array}$ & z & $\mathrm{p}$ \\
\hline \multirow{5}{*}{ Cost } & SCF & $\rightarrow$ & $\mathrm{SCP}$ & 0.229 & 0.34 & 2.183 & $.029 * *$ \\
\hline & EU & $\rightarrow$ & SCP & 0.211 & 0.35 & 2.078 & $.038 * *$ \\
\hline & $\mathrm{SCF}$ & $\rightarrow$ & IS & 0.132 & 0.31 & 2.105 & $.035 * *$ \\
\hline & $\mathrm{SCP}$ & $\rightarrow$ & IS & 0.153 & 0.24 & 1.784 & $.049 * *$ \\
\hline & IS & $\rightarrow$ & $\mathrm{C}$ & 0.882 & 0.29 & 2.447 & $.014 * *$ \\
\hline \multirow{5}{*}{ Flexibility } & $\mathrm{SCF}$ & $\rightarrow$ & IS & 0.172 & 0.43 & 2.659 & $.008 * *$ \\
\hline & $\mathrm{SCP}$ & $\rightarrow$ & SCP & 0.205 & 0.3 & 1.922 & $.048 * *$ \\
\hline & EU & $\rightarrow$ & $\mathrm{SCP}$ & 0.199 & 0.33 & 2 & $.046^{* *}$ \\
\hline & IS & $\rightarrow$ & SCP & 0.279 & 0.17 & 1.664 & $.050 * *$ \\
\hline & $\mathrm{SCP}$ & $\rightarrow$ & $\mathrm{F}$ & 0.65 & 0.35 & 3.788 & $.000^{* * *}$ \\
\hline \multirow{6}{*}{ Response } & SCF & $\rightarrow$ & IS & 0.186 & 0.45 & 2.727 & $.006 * * *$ \\
\hline & $\mathrm{SCF}$ & $\rightarrow$ & $\mathrm{SCP}$ & 0.184 & 0.27 & 1.748 & $.047 * *$ \\
\hline & EU & $\rightarrow$ & $\mathrm{SCP}$ & 0.214 & 0.35 & 2.11 & $.035 * *$ \\
\hline & IS & $\rightarrow$ & $\mathrm{SCP}$ & 0.257 & 0.16 & 1.721 & $.049 * *$ \\
\hline & $\mathrm{SCP}$ & $\rightarrow$ & $\mathrm{R}$ & 0.37 & 0.26 & 2.646 & $.008 * * *$ \\
\hline & IS & $\rightarrow$ & $\mathrm{R}$ & 0.471 & 0.2 & 1.721 & $.049^{* *}$ \\
\hline \multirow{5}{*}{ Delivery } & $\mathrm{SCF}$ & $\rightarrow$ & $\mathrm{SCP}$ & 0.229 & 0.34 & 2.161 & $.031 * *$ \\
\hline & EU & $\rightarrow$ & $\mathrm{SCP}$ & 0.228 & 0.37 & 2.2 & $.028 * *$ \\
\hline & $\mathrm{SCF}$ & $\rightarrow$ & IS & 0.112 & 0.28 & 1.913 & $.046 * *$ \\
\hline & $\mathrm{SCP}$ & $\rightarrow$ & IS & 0.134 & 0.22 & 1.957 & $.048 * *$ \\
\hline & $\mathrm{SCP}$ & $\rightarrow$ & D & 0.593 & 0.31 & 3.521 & $.000 * * *$ \\
\hline \multirow{5}{*}{ Financial } & $\mathrm{SCF}$ & $\rightarrow$ & $\mathrm{SCP}$ & 0.234 & 0.35 & 2.225 & $.026^{* *}$ \\
\hline & EU & $\rightarrow$ & SCP & 0.211 & 0.35 & 2.07 & $.038^{* *}$ \\
\hline & SCF & $\rightarrow$ & IS & 0.111 & 0.25 & 1.904 & $.050 * *$ \\
\hline & SCP & $\rightarrow$ & IS & 0.149 & 0.27 & 1.784 & $.047 * *$ \\
\hline & SCP & $\rightarrow$ & $\mathrm{F}$ & 0.44 & 0.22 & 2.683 & $.000 * *$ \\
\hline
\end{tabular}

$* * * p<0.001 * * p<0.05$

Table 8. Summarized information on the hypotheses established in the study

\begin{tabular}{|cccccccc|}
\hline \multirow{2}{*}{ Model } & \multicolumn{7}{c|}{ Hypothesis } \\
\cline { 2 - 7 } & $\mathrm{H} 1$ & $\mathrm{H} 2$ & $\mathrm{H} 3$ & $\mathrm{H} 4$ & $\mathrm{H} 5$ & $\mathrm{H} 6$ & $\mathrm{H} 7$ \\
\hline Cost & Accepted & Rejected & Accepted & Accepted & Accepted & Accepted & Rejected \\
Flexibility & Accepted & Rejected & Accepted & Accepted & Accepted & Rejected & Accepted \\
Response & Accepted & Rejected & Accepted & Accepted & Accepted & Accepted & Accepted \\
Delivery & Accepted & Rejected & Accepted & Accepted & Accepted & Rejected & Accepted \\
Financial & Accepted & Rejected & Accepted & Accepted & Accepted & Rejected & Accepted \\
\hline
\end{tabular}

\subsection{Delivery Model}

The model developed for the delivery performance (D), which is one of the subdimensions of the business performance scale, is presented in Figure 5 , and the results of the model are summarized in Table 7. The model indicates that the DP variable was significantly affected by the SCP variable. As can be seen from Table 6, $x^{2} / d f$ was 1.697 in the delivery model and therefore, the validity of the model was within acceptable limits. In the delivery model, as in the case of the flexibility model, $1^{\text {st }}$, $3^{\text {rd }}, 4^{\text {th }}, 5^{\text {th }}$, and $7^{\text {th }}$ hypotheses were accepted and the $2^{\text {nd }}$ and $6^{\text {th }}$ hypotheses were rejected. 


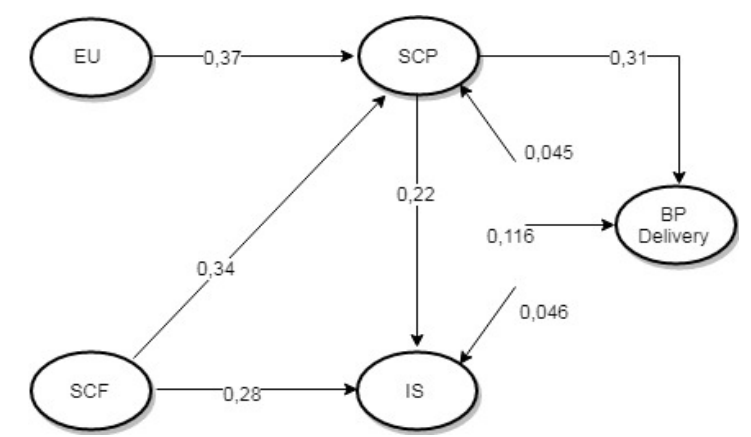

Figure 5. The structural equation of the delivery model

\begin{tabular}{|c|c|}
\hline Structural Equations & $\mathrm{R}^{2}$ \\
\hline Delivery $=0.31 * \mathrm{SCP}$ & $\% 10$ \\
\hline $\mathrm{IS}=0.22 * \mathrm{SCP}+0.28 * \mathrm{SCF}$ & $\% 21$ \\
\hline $\mathrm{SCP}=0.34 * \mathrm{SCF}+0.37 * \mathrm{EU}$ & $\% 44$ \\
\hline
\end{tabular}

\subsection{Financial Model}

Figure 6 shows the financial model, which is the fifth model proposed in the study. The summarized statistics are presented in Table 7. The analysis of the model showed that $x^{2} / d f$ was 1.699 and therefore, the validity of the model was within acceptable limits.

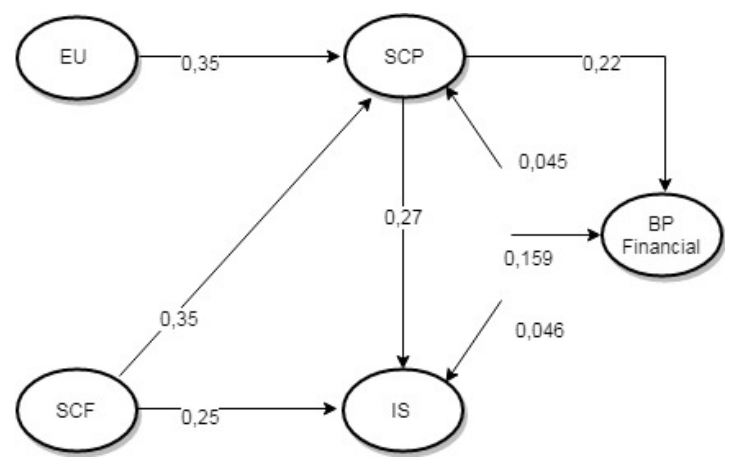

Figure 6. The structural equation of the financial model

\begin{tabular}{|c|c|}
\hline Structural Equations & $\mathrm{R}^{2}$ \\
\hline Financial $=0.440 * \mathrm{SCP}$ & $\% 5$ \\
\hline $\mathrm{IS}=0.111 * \mathrm{SCF}+0.149 * \mathrm{SCP}$ & $\% 22$ \\
\hline $\mathrm{SCP}=0.234 * \mathrm{SCF}+0.21 * \mathrm{EU}$ & $\% 42$ \\
\hline
\end{tabular}

In the model, $22 \%$ of the $\mathrm{BP}$ variable was explained. The positive influence coefficients indicate that as the SCF and SCP variables increase, the BP variable will also increase. Moreover, $42 \%$ of the SCP variable was explained in the model. According to the financial model, the $1^{\text {st }}, 3^{\text {rd }}, 4^{\text {th }}, 5^{\text {th }}$, and $7^{\text {th }}$ hypotheses were accepted, while the $2^{\text {nd }}$ and $6^{\text {th }}$ hypotheses were rejected.

The summarized information on the results obtained for the five different models proposed in the study is presented in Table 7, and the results on the hypotheses established in the study are summarized in Table 8. The results showed that the $1^{\text {st }}, 3^{\text {rd }}, 4^{\text {th }}$, and $5^{\text {th }}$ hypotheses were accepted in all models, while the $2^{\text {nd }}$ hypothesis (environmental uncertainties in the supply chain affect information sharing) was rejected in all models. This reveals that environmental uncertainties do not affect information sharing. The $6^{\text {th }}$ hypothesis was accepted in the cost and response models, while it was rejected in the flexibility, delivery, and financial models. Furthermore, the $7^{\text {th }}$ hypothesis was rejected only in the cost model and accepted in the other models.

\section{Conclusion and Future Work}

To achieve a competitive advantage, many firms focus more on supply chains. Therefore, they consider various ways to improve supply chain management. In the study, the relationships between the performance indicators of 203 businesses operating within the ISO 1000 manufacturing sector and factors that may affect these indicators were investigated using the Structural Equation Model (SEM). In studies investigating the factors affecting business performance, a single variable is often used as a measure of performance. As a novel contribution to the bulk of studies, five different performance variables were included in the study and the models were developed by defining these variables for which measurements could be carried out using multiple indicators as latent variables. The study employed cost, flexibility, response, delivery, and financial performance as the measures of performance since they are the commonly used theoretical business performance indicators. The sample of the study was made up of the data collected between December 2015 and April 2016 from a total of 203 ISO 1000 firms. In the study, the models were developed and analyzed with respect to the five performance indicators. More specific findings and results of the study are summarized below:

The supply chain process and information sharing contribute significantly to the improvement of business performance. Positive significant relationships were found for the five models proposed in the study. The conclusions drawn for the five structural models proposed in the study are as follows:

(1) All models are, first of all, adequately valid and reliable. 
(2) In all models, the environmental uncertainty variable did not affect information sharing.

(3) The influence of information sharing on business performance was significant only in the cost and response models.

(4) The supply chain process positively affected business performance in all models, except for the cost model.

(5) In all models, environmental uncertainties affected the supply chain process; supply chain flexibility affected the supply chain process and information sharing; effective information sharing accelerated the supply chain process.

(6) Of the cost performance, $8 \%$ was explained by information sharing,

(7) Of the flexibility performance, $12 \%$ was explained by the supply chain process,

(8) Of the response performance, $15 \%$ was explained by the supply chain process and supply chain flexibility,

\section{Appendix A. The scales used in the questionnaire}

I.

ENVIRONMENTAL UNCERTAINTY

- Customer Uncertainty

- $\quad$ Supplied Uncertainty

- Technology Uncertainty

- Demand Uncertainty

II. SUPPLY CHAIN FLEXIBILITY

- $\quad$ Supplier Flexibility

- $\quad$ Production Flexibility

- Product Development Flexibility

- Delivery Flexibility

- $\quad$ Supply Flexibility

III. SUPPLY CHAIN PROCESS

- Planning

- Supply

- Production

- Delivery

- Return Process

IV. INFORMATION SHARING

- Information Quality

- Supplier information and amount

- Manufacturer information and amount

- Information technology use

V. BUSINESS PERFORMANCE

Cost

- Unit product cost of the primary product
(9) Of the delivery performance, $10 \%$ was explained by the supply chain performance,

(10) Of the financial performance, $5 \%$ was explained by the supply chain process.

For further studies, improving the questionnaire with more extensive questions to include other factors such as confidence and reputation in the analysis is recommended. Expanding this study to include firms that lie outside the scope of ISO 1000 may be beneficial for extending its results to all sectors and businesses. This study is an initial study carried out using an SEM. A more comprehensive study can take the relationship obtained by using the SEM into consideration and develop hybrid models that can predict business performance by employing different methods.

This study was conducted on companies that are affiliated to different supply chains, rather than a single supply chain. Conducting the study on companies in a specific supply chain by narrowing down the scope of the study may ensure obtaining healthier results.
- Unit direct labor cost of the primary product

- Unit material cost of the primary product

- Total production cost

Flexibility

- Production volume flexibility

- Production labor flexibility

- Production diversity flexibility

Response

- Production delivery time

- Seller delivery time

- Cash cycle time

- Delivery of the customer demands

- Product development cycle time

- Delivery reliability/dependability

Delivery

- Exchange / installation times

- On-time delivery

- Perfect order fill rate

Financial

- Sales revenue

- Return on assets

- Return on sales

- Asset turnover

- $\quad$ Profit before interest tax as \% revenue 


\section{REFERENCES}

1. Baihaqi, I. \& Sohal, A. S. (2013). The impact of information sharing in supply chains on organisational performance: an empirical study, Production Planning \& Control: The Management of Operations, 24(8-9), 743-758.

2. Byrne, B. M. (2010). Structural Equation modeling with AMOS: basic concepts, applications, and programming (2nd ed.). New York-London: Taylor \& Francis Group.

3. Demirel, Y. (2009). A research on the effect of information and information sharing on business performance, Journal of Administrative Sciences, 6(1), 199-216.

4. Dwaikat, N. Y. (2016). Flexibility through information sharing evidences from the automotive industry in Sweden, KTH Royal Institute of Technology School of Industrial Engineering and Management Department, Ph.D thesis. Stockholm, Sweden.

5. Erjiang, E., Peng, G., Tian, X. \& Chen, Q. (2016). Online cooperative promotion and cost sharing policy under supply chain competition, Mathematical Problems in Engineering, Vol. (2016), 1-11.

6. Fiala, P. (2005). Information sharing in supply chains, Omega, 33(5), 419-423.

7. Golob, T. F. (2003). Structural equation modeling for travel behavior research, Transportation Research Part B. Methodological, 37(1), 1-25.

8. Hsu, C.-C., Kannan, V.R., Tan, K.-C.\& Leong, G. K. (2008). Information sharing, buyersupplier relationships and firm performance a multi-region analysis, International Journal of Physical Distribution \& Logistics Management, 38(4), 296-310.

9. Hung, W.-H., Ho, C.-F., Jou, J.-J. \& Tai, Y.M. (2011). Sharing information strategically in a supply chain: antecedents, content and impact, International Journal of Logistics Research and Applications: A Leading Journal of Supply Chain Management, 14(2), 111-133.

10. Huo, B., Zhao, X. \& Zhou, H. (2014a). The effects of competitive environment on supply chain information sharing and performance: An empirical study in China, Production and Operations Management, 23(4), 552-569.

11. Huo, B., Qi, Y., Wang, Z. \& Zhao, X. (2014b). The impact of supply chain integration on firm performance: The moderating role of competitive strategy, Supply Chain
Management: An International Journal, 19(4), 369-384.

12. Jin, Y., Vonderembse, M., Ragu-Nathan, T. S. \& Smith, J. T. (2014). Exploring relationships among IT-enabled sharing capability, supply chain flexibility, and competitive performance, International Journal of Production Economics, 153(2014), 24-34.

13. Kocaoglu, B. (2013). A SCOR based model for integrating strategic and operational objectives for supply chain performance measurement, Ph.D thesis, Y1ldiz Teknik University. İstanbul, Turkey.

14. Kotzab, H., Teller, C., Grant, D. B. \& Sparks, L. (2011). Antecedents for the adoption and execution of supply chain management, Supply Chain Management: An International Journal, 16(4), 231-245.

15. Lee, H. L. (2002). Aligning supply chain strategies with product uncertainties, California Management Review, 44(3), 105-119.

16. Lee, H. L. \& Whang, S. (2000). Information sharing in a supply chain, International Journal of Manufacturing Technology and Management, 1(1), 79-93.

17. Li, G., Yan, H., Wang, S. \& Xia, Y. (2005). Comparative analysis on value of information sharing in supply chains, Supply Chain Management: An International Journal, $10(1), 34-46$.

18. Li, S. \& Lin, B. (2006). Accessing information sharing and information quality in supply chain management, Decision Support Systems, 42(2006), 1641-1656.

19. Liao, Y. (2006). Supply chain flexibility: The antecedents, driving forces and impacts on performance, $\mathrm{Ph} . \mathrm{D}$ thesis, The University Of Toledo. USA.

20. Marinagi, C., Trivellas, P. \& Reklitis, P. (2015). Information quality and supply chain performance: The mediating role of information sharing, Procedia Social and Behavioral Sciences, 175(1), 473-479.

21. Martin, R. (2002). Data sharing between supply chain members, Ph.D thesis, Clemson University.

22. Paulraj, A. \& Chen, I. J. (2007). Environmental uncertainty and strategic supply management: a resource dependence perspective and performance implications, 
Journal of Supply Chain Management, 43(3), 29-42.

23. Prajogo, D. \& Olhager, J. (2012). Supply chain integration and performance: The effects of long-term relationships, information technology and sharing, and logistics integration, Int. J. Production Economics, 135, 514-522.

24. Qrunfleh, S. \& Tarafdar, M. (2014). Supply chain information systems strategy: impacts on supply chain performance and firm performance, International Journal of Production Economics, 147, 340-350.

25. Raykov, T. (1997). Scale reliability, cronbach's coefficient alpha, and violations of essential tau-equivalence with fixed congeneric components, Multivariate Behavioral Research, 32, 329-353.

26. Sagbas, M. (2015). The impact of information technologies, agility and integration on operational and financial performance in supply chain management, Ph.D thesis, Beykent University. Turkey.

27. Sahin, F. \& Robinson Jr., E. P. (2005). Information sharing and coordination in make-to-order supply chains, Journal of Operations Management, 23(2005), 579-598.

28. Schermelleh-Engel, K., Moosbrugger, H. \& Müller, H. (2003). Evaluating the fit of structural equation models: Tests of significance and descriptive goodness-offit measures, Methods of Psychological Research Online, 8(2), 23-74.

29. Schumacker, R. E. \& Lomax, R. G. (2004). A Beginner's Guide to Structural Equation modeling (2nd ed.). Mahlah, New Jersey, London: Lawrence Erlbaum Associates.

30. Shin, H., Collier, D. A. \& Wilson, D. D. (2000). Supply management orientation and supplier/buyer performance, Journal of Operations Management, 18, 317-333.

31. Singh, P. J. \& Power, D. (2013). Innovative knowledge sharing, supply chain integration and firm performance of Australian manufacturing firms, International Journal of Production Research, 52(21), 6416-6433.

32. Topoyan, M. (2009). Effect of interorganizational systems on supply chain flexibility, Ph.D thesis, Dokuz Eylül University. Turkey.

33. Torkul, O., Calli F., Ozceylan, D., Goksu, A. \& Geyik, A. K. (2007). Information sharing chain design: Is this innovative aproach for integrated supply chain? In $4^{\text {th }}$ International
Conference on Responsive Manufacturing, $17-19^{\text {th }}$ September, Nottingham, UK.

34. Upton, D. M. (1994). The management of manufacturing flexibility, California Management Review, 36(2), 72-89.

35. Vickery, S., Calantone, R. \& Droge, C. (1999). Supply chain flexibility: An empirical study, Journal of Supply Chain Management, 35(3), 16-24.

36. Wang, Z. \& Wang, N. (2012). Knowledge sharing, innovation and firm performance, Expert Systems with Applications, 39(10), 8899-8908.

37. Wiengarten,F.,Humphreys,P., Cao, G., Fynes, B. \& McKittrick, A. (2010). Collaborative supply chain practices and performance: Exploring the key role of information quality, Supply Chain Management: An International Journal, 15(6), 463-473.

38. Wong, C. Y., Boon-Itt, S. \& Wong, C. W. (2011). The contingency effects of environmental uncertainty on the relationship between supply chain integration and operational performance, Journal of Operations management, 29(6), 604-615.

39. Wu, L., Chuang, C. H. \& Hsu, C. H. (2014). Information sharing and collaborative behaviors in enabling supply chain performance: A social exchange perspective, Int. J. Production Economics, 148, 122-132.

40. Ye, F. \& Wang, Z. (2013). Effects of information technology alignment and information sharing on supply chain operational performance, Computers \& Industrial Engineering, 65(3), 370-377.

41. Yigitbasioglu, O. M. (2010). Information sharing with key suppliers: A transaction cost theory perspective, International Journal of Physical Distribution \& Logistics Management, 40(7), 550-578.

42. Youn, S. H., Yang, M. G., Kim, J. H. \& Hong, P. (2014). Supply chain information capabilities and performance outcomes: An empirical study of Korean steel suppliers, International Journal of Information Management, 34(3), 369-380.

43. Zhou, H. (2003). The role of supply chain processes and information sharing in supply chain management, Ph.D thesis, The Ohio State University. USA.

44. Zhou, H. \& Benton Jr., W. C. (2007). Supply chain practice and information sharing, Journal of Operations Management, 25, 1348-1365. 